\section{Cross-cultural and educational aspects of the Ponzo perspective illusion*}

\author{
HERSCHEL W. LEIBOWITZ \\ The Pennsylvania State University, University Park, Pennsylvania 16802 \\ and \\ HERBERT A. PICK, JR. \\ University of Minnesota, Minneapolis, Minnesota 44544
}

The magnitude of the Ponzo illusion was determined for two groups of Ugandans, university students and villagers. For the university population, increase in the depth cues in which the illusion was embedded produced an increase in illusion magnitude similar to that observed among students in an American university. For the villagers, however, no illusion was observed for any of the stimulus conditions. Since the environmental ecology of the two groups was similar, the lack of illusion among the villagers cannot be attributed to differential past history of exposure to depth cues. Rather it is hypothesized that responses to two-dimensional stimuli are determined by both depth and flatness cues, and that the responses of the uneducated observers were determined primarily by flatness cues.

A large number of experimental studies have demonstrated that members of various cultural groups produce differential responses on perceptual tasks. Some of the better known examples include the demonstrations by Segall, Campbell, and Herskovits (1966) of cross-cultural differences on a number of geometric-optical visual illusions, Allport and Pettigrew's (1957) work with the trapezoidal illusion, a series of perceptual studies by Deregowski $(1967,1968 \mathrm{a}, \mathrm{b}, 1969)$, and Hudson's (1967) research with the perception of depth in pictures. These data are usually interpreted as resulting from differential past histories of exposure to the critical perceptual cues involved, either in the form of experience with real-life cues from the surrounding environment, or with the conventional three-dimensional cues used in pictures, photographs, and other two-dimensional representations. The influence of experience with real-life environmental cues is the basis of the "ecological hypothesis," which assumes that if the cues involved have a differential frequency of occurrence in the environments of different cultural groups, they will acquire differential strengths that will be reflected in the responses made to them on perceptual tasks.

Recently, the Ponzo perspective

*Supported by Grant MH08061 from the National Institute of Mental Health, by a grant from the Carnegie Foundation to Makerere University and Syracuse University, and by Grant 1 PO1 HD05027 from the National Institute of Child Health and Development. These data were presented to the 1971 meeting of the Eastern Psychological Association. The authors are indebted to Mr. Robert J. Miller for help in the preparation of the manuscript. illusion, Fig. 1, was presented to university students in Pennsylvania and Guam (Leibowitz, Brislin, Perlmutter, \& Hennessy, 1969). Considering Fig. 1B, in which the Ponzo illusion is embedded in railroad tracks, the overestimation of the horizontal line nearer to the apex of the figure was $32 \%$ for the Pennsylvania students. However, for the Guamanians, who had much less exposure to railroad tracks (only one short spur railroad exists in Guam) the magnitude of the illusion was only $18 \%$. This difference was interpreted as resulting from the greater effectiveness, stemming from different past history, of the depth cue represented by the converging lines of the tracks for the Pennsylvania observers as compared with the Guamanians. 1

The present experiment represents an extension of the original study among two groups of Ugandans, college students at Makerere University and villagers from the Kampala surround. The university students represent a replication of the data obtained from the Pennsylvania students since they were of the same educational level and had had experience in a "carpentered" urban environment very similar to that experienced by the Pennsylvania students. In addition, the question of interpretation of instructions, attitude, and demand characteristics, variables that play a significant role in perceptual studies, will be minimal for these Ss who are of the same educational level. On the other hand, rural Ugandans would be expected to differ on a number of dimensions that might influence responses to the pictorial Ponzo stimuli. Their visual environments would not be expected to differ significantly from those of the urban Ugandans or the Pennsylvanians since the rural areas show many examples of converging lines and perspective, most conspicuously in the form of both dirt and tarmac roads, square homes containing doors and windows, and rectangular farm plots reminiscent of rural America during the early part of this century. However, differences between the two groups in educational level and past experience with two-dimensional reproductions are pronounced: many of the villagers had not attended school and those who had had not gone beyond the third grade. Books were not typically present in the home. Thus, the use of the same stimuli in these studies provides an opportunity to ascertain whether differences exist between groups who live in similar visual ecologies, but who differ significantly with respect to educational level and exposure to two-dimensional reproductions.

\section{METHOD AND PROCEDURE}

The method and procedure were identical to that followed in the previous study (Leibowitz, Brislin, Perlmutter, \& Hennessy, 1969) and utilized the same stimuli as illustrated in Fig. 1. For all four stimulus configurations, the upper horizontal line, or board, subtended the same visual angle while the lower boards or lines varied systematically in their horizontal dimension. The Ss were asked to indicate which line or board was larger. The subjective equality value was defined as the midpoint of the region of uncertainty bounded by the sizes of the lower line or board, which were consistently called "larger than" and "smaller than" the upper line or board. The magnitude of the illusion is the overestimation, in percent, of the upper line or board. For the photographs, Fig. 1A and 1B, the upper board was actually $182.9 \times$ $10.2 \mathrm{~cm}$ and located $18.29 \mathrm{~m}$ from the camera, which had a $90-\mathrm{mm}$ lens. The negatives were enlarged 6.7 times, producing an image width of the upper board of $6.0 \mathrm{~cm}$. The lower boards were chosen so as to produce an image size on the prints varying from 4.7 to $10, \mathrm{~cm}$, in equal steps. For the geometric stimuli, Fig. 1C and 1D, the dimensions of the upper and lower lines were identical to those on the photographs.

The $\mathrm{S}$ was first shown a stimulus configuration for which the lower line was clearly larger or smaller than the upper and asked to indicate which one was the larger. The next stimulus was chosen to elicit the "larger than" response for the other line. This procedure served to indicate whether 


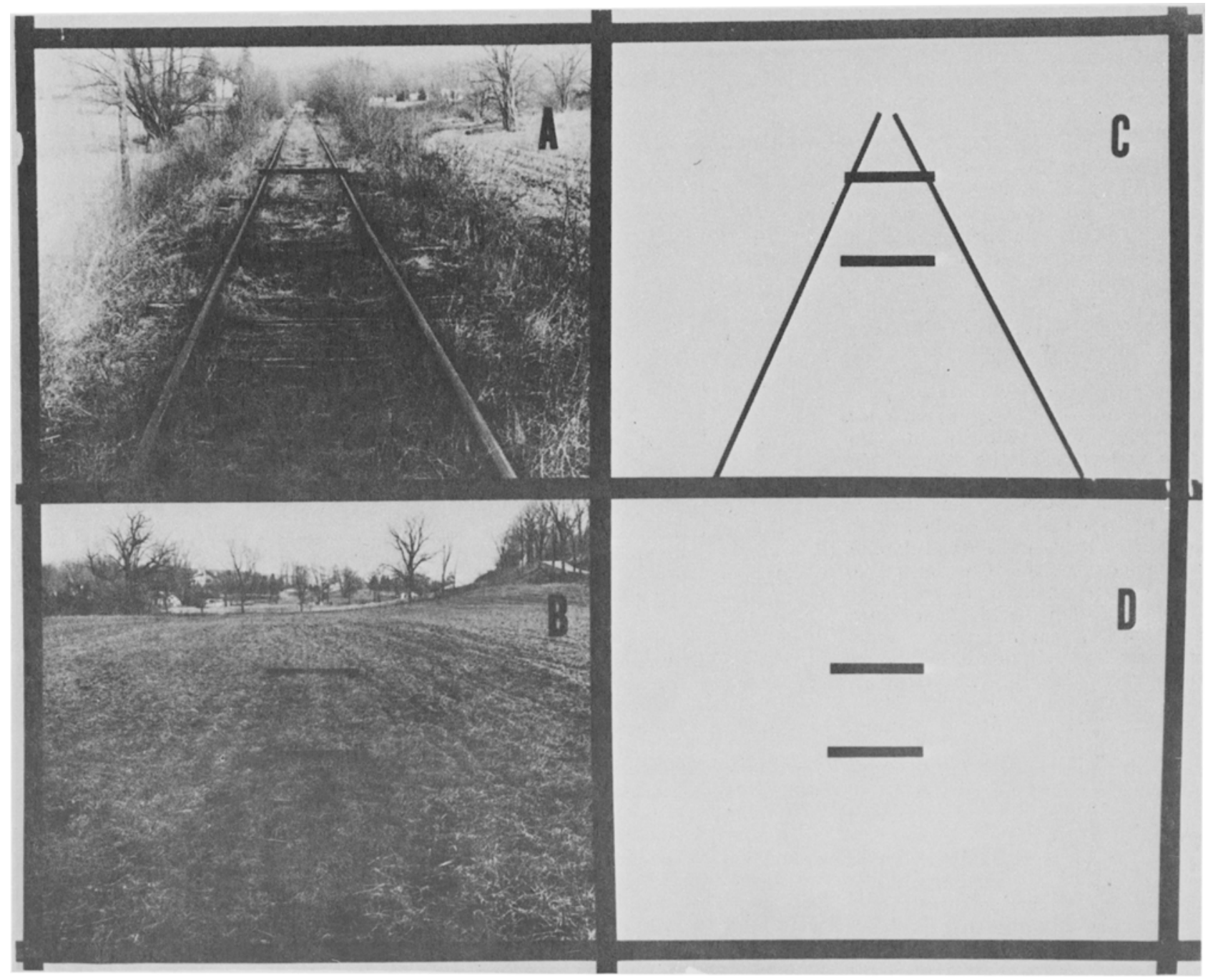

Fig. 1. The stimuli used in this study. The extent of the horizontal lines in these examples is the same.

the $S$ understood the instructions. The other members of the series were then presented to $S$. At the end of the series, large differences were again presented in order to confirm that Ss maintained the same instructional set. Order of presentation for the four types of stimulus was determined by a Latin-square design.

The $S$ population consisted of 20 Makerere University students and 120 villagers. All Ss were tested by a native research assistant under the close supervision of the junior author, a visiting professor at Makerere University. For the villagers, the instructions were translated into Luganda and checked by translation back to English by a second speaker.

\section{RESULTS}

The value of the upper line, which matched the lower, was determined by interpolation as the midpoint of the region at which the S's responses changed. The magnitude of the illusion, or the percentage overestimation of the upper line, is plotted in Fig. 2 for the four stimulus configurations. For comparison purposes, data from the previous study for the Pennsylvania and Guamanian Ss have also been plotted on this graph.

It will be noted that, for the Ugandan college students, the overestimation is lowest for the plain background and increases systematically with addition of the geometric converging lines, the plowed field photographic background, and the railroad tracks. This function is similar to that obtained from the Pennsylvania college students. However, the data for the villagers is striking in that no illusion or overestimation is observed for any of the four sets of stimuli, either for groups or for individuals.

\section{DISCUSSION \\ The similarity of the college}

Ugandans as compared with Pennsylvania college students was not unexpected in view of the similarities of their backgrounds and visual experiences. In effect, the data from the college Ugandans represent a replication of the previous study with Pennsylvania college students.

The lack of response among the villagers is very striking. None of the stimuli produced any illusion whatsoever. Normally, when depth cues are ineffective in cross-cultural studies, one looks for differences in the past history of exposure of Ss to the cues in question. However, this is not appropriate in the present situation since the rural environment in which the villagers live is, in terms of depth cues, similar to that experienced by both the Ugandan and Pennsylvania college students. There are many examples of buildings, roads, plowed fields, etc., in their environment and it is thus most unreasonable to assume that the depth 
cues present in the stimuli have no previous association whatsoever among these Ss. Any explanation of their lack of response must assume that these depth cues are familiar to them but for some reason are not effective in the present situation.

Following this line of reasoning, it is instructive to examine the conditions under which the stimuli are presented. All of the cues are incorporated in two-dimensional presentations and are viewed binocularly. As Schlosberg (1941) has pointed out, two-dimensional representations involve not only depth cues, but flatness cues as well. The absence of stereopsis while viewing a two-dimensional representation binocularly, the visibility of the surface and edge of the stimuli, the context in which they are viewed, and the cognitive awareness that there is no depth in a piece of cardboard all provide cues to flatness. When flatness cues are reduced, the effectiveness of depth cues is enhanced, as evidenced by the plastic depth effect that occurs when viewing photographs under conditions that eliminate or reduce flatness cues (Ames, 1925; Gregory, 1966; Hardy \& Perrin, 1932; Schlosberg, 1941; Smith \& Gruber, 1958). Similarly, the tendency towards size constancy in photographs has been shown to be greater when viewed monocularly than when viewed binocularly (Leibowitz, Bussey, \& McGuire, 1957). Presumably binocular observation of a two-dimensional reproduction introduces flatness cues, since binocular disparity that normally accompanies binocular vision is absent. Furthermore, freedom of head movement provides motion parallax information that the reproduction is in fact flat.

If cues to flatness can attenuate the effectiveness of these cues to depth for educated Ss in the United States, a possible explanation of the Ugandan village data would follow by assuming that the flatness cues present in the testing situation are even more effective for them. The perceptual learning process is assumed to involve not only increased strength of depth cues, but also the ability to disregard or inhibit flatness cues. It seems reasonable to assume that frequent exposure to two-dimensional presentations in photographs, books, newspapers, cinema, and television, which is a normal part of the educational and day-to-day living processes, results in acquisition of the ability to disregard flatness cues and would be consistent with a differential response on the part of the educated college Ugandans as opposed to the uneducated villagers.

This explanation, although both qualitative and speculative, is

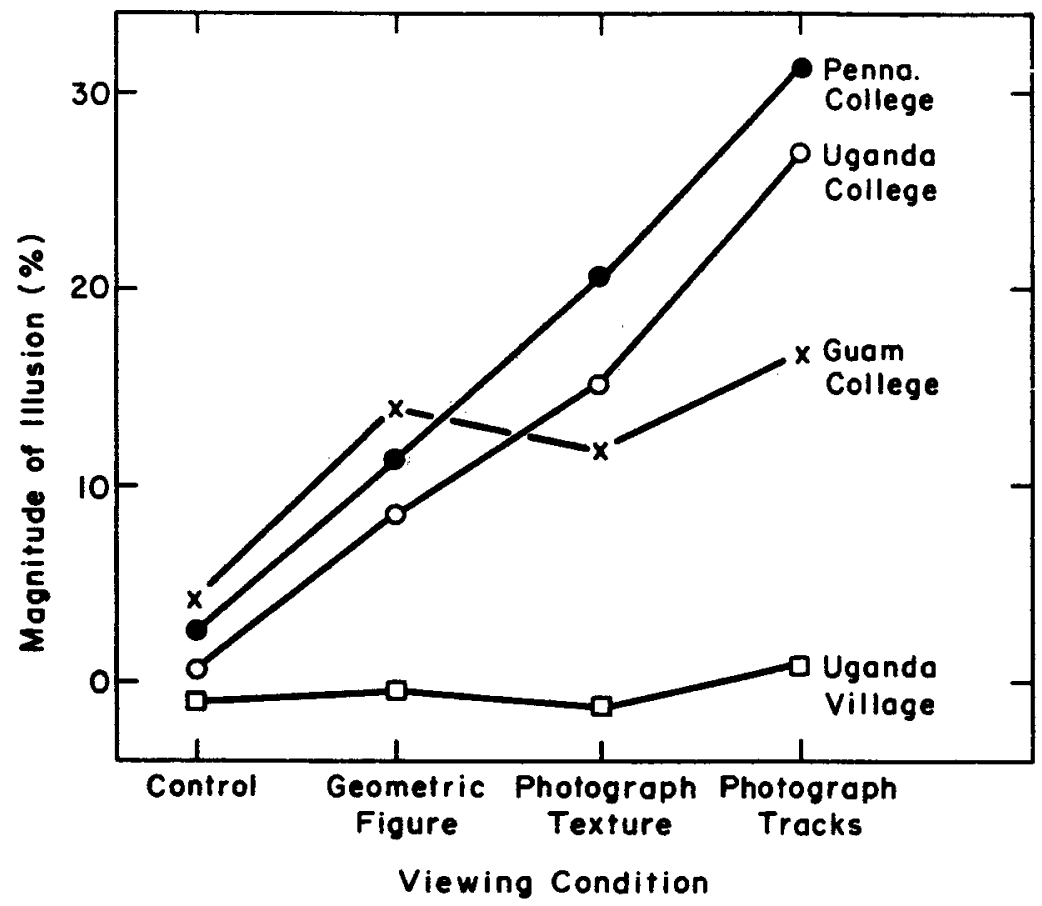

Fig. 2. The magnitude of the Ponzo illusion for the various conditions of the experiment. In each case, the illusion represents the percentage overestimation of the upper member of the pairs of horizontal lines illustrated in Fig. 1. The Pennsylvania college and Guam college data are from a previous experiment.

fortunately testable. If the same stimuli are presented under conditions that eliminate both perceptual and cognitive cues to flatness, the depth dependent illusory response among the villagers would be expected to increase. This could be accomplished by monocular viewing of transparencies under conditions for which depth would not be ruled out by the experimental arrangement, i.e., presentation of the stimuli in a window. If observation under conditions that minimize flatness cues produces a greater response on the part of the rural Ugandans than in the present experiment, the present data would be consistent with the proposed interpretation, which accounts for the magnitude of the illusory responses in terms of the relative strengths of depth and flatness cues.

\section{REFERENCES}

ALLPORT, G. W., \& PETTIGREW, T. F. Cultural influence on the perception of movement: The trapezoidal illusion among Zulus. Journal of Abnormal \& Social Psychology, 1957, 55, 104-1 13.

AMES, $A$. The illusion of depth from single pictures. Journal of the Optical Society of America, $1925,10,137-148$.

DEREGOWSKI, J. The horizontal-vertical illusion and the ecological hypothesis. International Journal of Psychology, 1967, 2, 269-273.

DEREGOWSKI, J. Difficulties in pictorial depth perception in A frica. British Journal of Psychology, 1968a, 59, 195-204.

DEREGOWSKI, J. Pictorial recognition in subjects from a relatively pictureless environment. A frican Social Research. $1968 \mathrm{~b}, 5,356-364$.
DEREGOWSKI, J. A pictorial perception paradox. Acta Psychologia, 1969, 31 365-374.

GREGORY, R. L. Eye and brain: The psychology of seeing. New York: McGraw-Hill, 1966.

HARDY, A. L., \& PERRIN, F. H. The principles of optics. New York : MeGraw-Hill, 1932.

HUDSON, w. The study of the problem of pictorial perception among unacculturated groups. International Journal of Psychology, 1967, 2, 90-107.

LEIBO WITZ, H. W., BRISLIN, R., PERLMUTTER, L., \& HENNESSY, R. Ponzo perspective illusion as a manifestation of space perception. Science, 1969, 166, 1174-1176.

LEIBOWITZ, $\dot{H}$. W., BUSSEX, T., \& McGUIRE, $P$. Shape and size constancy in photographic reproductions. Journal of the Optical Society of A merica, 1957, 47, 658-661.

SCHLOSBERG, H. Stereoscopic depth from single pictures. American Journal of Psychology, 1941, 54,601-605.

SEGALL, M. H., CAMPBELL, D. T., \& HERSKOVITS, M. J. The influence of culture on visual perception. Indianapolis: Bobbs-Merrill, 1966.

SMITH, O., \& GRUBER, H. Perception of depth in photographs. Perceptual \& Motor Skills, 1958, 8, 307-313.

\section{NOTE}

1. The Pennsylvania Ss also produced a larger illusion (21\%) than the Guamanians (12\%) on the texture photograph (Fig. 1C). However, with the geometrical figure (1A), the Guamanians produced a slightly greater illusion. This implies that the critical differences do not result from linear perspective per se, but from the presence of texture and other monocular cues in the photographs.

(Received for publication March 27, 1972; revision received July 19,1972 .) 